about this latent sepsis, but now thinks that three months after the healing of the wound should be the minimum period before operation is attempted, and that in many cases it is as well to wait longer. The importance of maintaining the nutrition of the parts is thoroughly emphasized.

The various operations for the treatment of non-union are discussed : the step-cut operation for the humerus and forearm bones is as a rule very suitable.

The plan of introducing a long intramedullary peg from the trochanter in fractures of the upper end of the femur is distinctly ingenious, and although, as the author admits, the results in this series are not particularly good, yet it is a procedure which will probably become popular. The special section on bone grafting is excellent.

It is impossible to refer in detail to the other papers in this number on account of the limitations of space-not that they are less worthy of notice than those mentioned above, for they all show evidence of careful work.

There are various papers on nerve surgery and joint injuries of the upper extremity. One paper on the end-results of primary excision of the elbow, showing how bad they are when the re-section of bone has been extensive, should be remembered.

The usual high standard of illustrations, etc., is fully maintained.

Abstracts of War Surgery prepared by the Division of Surgery.-Surgeon-General's Office, St. Louis, U. S. A.: C. V. Mosley Company. Price $4 s$.

THEse abstracts were collected when America entered the war, the object being to place the surgical work which had been done by the various belligerents in a handy form in the hands of surgical instructors and surgical chiefs of war hospitals.

It was found that there was a wide demand for them : hence their present publication in book form.

- The various articles are collected under appropriate headings, i.e., wound infection and treatment, fractures, etc., etc.

The collection has been made from wide sources - in fact, from the literature of nearly all the fighting nations.

The extracts vary in length according to their importance, in some the original article being reproduced in full. The book gives in a compact way the chief points of the various papers and will enable the reader, if he desires any further information, to obtain the original article as the references are complete.

Tumours : Their Nature and Causation - By Dr. D'Emery. M.D., B.sc. (Lond.). Pp. 146. London: H. K. Lewis \& Co., 1918. Price 5s.

THIS little book is a special plea for the parasitic hypothesis of the causation of all, or almost all, tumours. If the author's three postulates be granted, viz., (1) an ultra-microscopic parasite, (2) intra-cellular or intra-nuclear site, and (3) that it produces a toxin which has the power of inducing cell division, a satisfactory explanation of tumour formation can be formulated. The author marshals his facts and arguments clearly and concisely, and the essay makes interesting reading. The final chapters in which he meets objections, which may be urged against the theory, show him to be a master of the art of debate.

\section{The Influence of Sunlight in the Production} of Cancer of the Skin.-By C. Norman Paul, M B., ch.M. Pp. 57. Lonảon: H K. Lewis \& Co., 1918. Price 10s. $6 d$

THIs book is an atlas with descriptive letterpress of the cancerous and precancerous conditions of the skin, in the rtiology of which sunlight is supposed to play a part. The majority of the plates illustrate the features of rodent ulcers, but in addition chronic solar dermatitis, cutaneous horn and epithelioma are illustrated, whilst xeroderma pigmentosum is described but not illustrated. The illustrations are reproductions from photographs and are on a large scale; on the whole they are very successful.

Surgical Applied Anatomy.-By Sir Frederick Treves, Bart., G.c.v.o., etc. Seventh Edition, revised hy ARTHUR KEITH, M D., F.r.c.s., and W. Colin Mackenzie, M.D., F.r.c.s. Tondon : Cassel \& Co., 1918. Price 10s. 6d. net.

There is little left for a reviewer to say about a book of such proved utility as Treves' Surgical Anatomy. The alterations, which the revisers have made in the book have been directed towards making it more useful to military surgeons, the sections on anatomy of nerves and on paralyses and joints having been somewhat expanded. The retention of the old nomenclature (the new terms being inserted in brackets) will be welcomed by many. Some new figures illustrating distribution of peripheral nerves will be useful, as also several figures of amputations. The present edition worthily maintains the reputation of this standard work.

"Fibroids" and Allied Tumours: Their Patho. logy, Clinical Features and Surgical Treatment.-By CUTHBERT LoCKYer, M D., B s., \&c 316 Illustrations and 37 Coloured Plates. Publishers: Macmillan \& Co., 1918.

THIs is a very fine and complete monograph, the principal interest of which lies in that part dealing with Adenomyomas, which, as the author rightly states, "have scarcely received the attention from British writers which is their due, and an extra-uterine origin for some of these growths needs emphasizing."

Part III deals with treatment, surgical and otherwise. One is pleased to see a whole chapter 